\title{
Respostas fisiológicas de cabras Anglonubianas a condições ambientais com temperatura elevada ${ }^{1}$
}

\author{
Physiological responses of Anglo Nubian female goats in the environmental conditions \\ with high temperature
}

MOUSINHO, Leeandro Rafaell Brandão²; CAMPELO, José Elivalto Guimarães ${ }^{3}$; SOUSA JÚNIOR, Severino Cavalcante de ${ }^{4}$; AZEVÊDO, Danielle Maria Machado Ribeiro $^{5}$; LEAL, Tânia Maria ${ }^{5}$; MOURA, Rosianne Mendes de Andrade da Silva ${ }^{2^{*}}$

${ }^{1}$ Parte da Dissertação primeiro autor.

${ }^{2}$ Universidade Federal do Piauí, Centro de Ciências Agrárias, Programa de Pós-Graduação em Ciência Animal, Teresina, Piauí, Brasil.

${ }^{3}$ Universidade Federal do Piauí, Centro de Ciências Agrárias, Departamento de Zootecnia, Teresina, Piauí, Brasil.

${ }^{4}$ Universidade Federal do Piauí, Centro de Ciências Agrárias, Departamento de Zootecnia, Bom Jesus, Piauí, Brasil.

${ }^{5}$ Embrapa Meio-Norte, Teresina, Piauí, Brasil.

*Endereço para correspondência: rosiannem@gmail.com

\section{RESUMO}

A raça Anglonubiana foi pesquisada com o objetivo de avaliar em fêmeas de diferentes idades e condições fisiológicas, indicadores de status térmico em resposta a condições ambientais com temperatura elevada. As cabras foram agrupadas em quatro classes de idade: com mais de 72 meses, de 36 a 72 , entre 18 e 36 e marrãs com 12 a 15 meses, e foram submetidas à estação de monta em agosto/setembro, com final de gestação em dezembro e lactação em fevereiro, meses nos quais registraram-se a temperatura retal, frequência cardíaca $\mathrm{e}$ respiratória, também o escore e peso corporal, mensurados no mesmo animal quando este se encontrava "não prenhe", "prenhe" e em "lactação", nesses meses, respectivamente. As mensurações ocorreram durante seis dias alternados em cada mês, com leituras entre $14 \mathrm{hs}$ e $17 \mathrm{hs}$, realizadas à sombra. Adotou-se delineamento casualizado com análise estatística num fatorial $4 \times 3$ (idade e período), com seis repetições. Constatou-se que, independente da idade, tamanho e estágio fisiológico as cabras Anglonubianas recorrem à elevação da frequência respiratória para complementar a dissipação de calor, que se mostrou eficiente em setembro sob temperatura ambiente elevada e baixa umidade do ar. As alterações nas características indicadoras de status térmico do animal, mais acentuadamente na temperatura retal, demonstram que o período do ano mais favorável à homeotermia corporal seja destinado a ocorrência de gestação e lactação.

Palavras-chave: adaptação, cabra, calor, idade, estágio fisiológico

\section{SUMMARY}

The Anglo Nubian breed was investigated with the objective of evaluating in females of different ages and physiological condition, thermal status indicators of the animal in response to environmental conditions with high temperature. The animals were grouped into four ages: with more than 72 months, of 36 to 72 , between 18 and 36 and gilts with 12 to 15 months. The goats were subjected to breeding season in August/September, end of gestation in December and lactation occurred in February, months in which the rectal temperature, heart rate and respiratory frequency, score and body weight, measured in the same animal when they were "not pregnant", "pregnant" and "lactation", in these months, respectively. The measurements occurred in the shade in six 
alternate days in each month, with readings between 14:0 and 17:0h. Randomized design has been used in $4 \times 3$ factorial experiments (ages and periods), with six repetitions. It was noted that, regardless of age, size and physiological stage, the goats using elevated respiratory rate to supplement heat dissipation, which proved to be efficient in September when the ambient temperature is high and the air humidity was low. Changes in thermal status indicator features of the animal, more sharply on rectal temperature, show that in period of the year more favorable to corporal homoeothermic must be designed to occurrence of pregnancy and lactation.

Keywords: adaptation, age, goat, heat, physiological stage

\section{INTRODUÇÃO}

O Nordeste concentra 90,6\% do rebanho caprino do Brasil, dos quais $17 \%$ situam-se no Piaú, com efetivo de 1.389.384 animais (IBGE, 2010). Embora com plantel expressivo, a caprinocultura é praticada com baixos índices zootécnicos atribuíveis ao uso limitado de tecnologias (SARMENTO et al., 2003), predominando a criação extensiva e animais expostos a condições ambientais adversas (ROCHA et al., 2009).

Os animais produzem com mais eficiência quando estão na zona de conforto térmico que, para caprinos situase entre 20 e $30^{\circ} \mathrm{C}$, na qual é mínimo o gasto de energia para homeotermia (BAÊTA \& SOUZA, 1997). Porém, apesar de conhecidos os efeitos prejudiciais do estresse térmico sobre os animais nos trópicos, estudos continuam sendo realizados para quantificá-los e minimizá-los (SILVA et al., 2010).

Raça adaptada ao calor no Nordeste é importante, pois os animais produzem sob condições ambientais que podem extrapolar o limite de conforto. O efeito do turno do dia e época do ano sobre variáveis ambientais tem sido constatado na região, bem como sobre parâmetros fisiológicos do animal e que raças têm apresentado capacidade para manter a homeotermia, mas com elevação da taxa respiratória (LUCENA et al., 2013; PEREIRA et al., 2011; SILVA et al., 2010).

A importância de avaliar a resposta fisiológica de raças exploradas em ambiente quente, é para buscar ajustes no manejo e torná-lo eficiente (AZEVEDO et al., 2005). Nessa perspectiva, a raça Anglonubiana, que já se encontra difundida na região, inserida nas condições ambientais e nos sistemas de criação (OLIVEIRA et al., 2008; ROCHA et al., 2009), tem se destacado. $\mathrm{Na}$ avaliação de raça para ambiente quente convém considerar que os animais apresentam necessidades térmicas específicas que é função do estágio de produção (DUKES \& SWENSON, 2006). Na gestação e lactação a matriz passa por alterações endócrinas com alteração na concentração de determinados hormônios (RODRIGUES et al., 2007) e a velocidade com que mudanças ocorrem é importante, pois pode limitar a capacidade de adaptação do animal, pela necessidade de homeostase.

A esse respeito, a manutenção de parâmetros fisiológicos da fêmea em níveis normais pode ser um bom indicador do grau de adequação da raça ao local de criação, pois é a cabra que permanece mais tempo no rebanho, se expondo a estresse de natureza diversa. Assim, objetivou-se nesta pesquisa avaliar o status térmico de fêmeas da raça Anglonubiana como resposta a exploração em ambiente de temperatura elevada. 


\section{MATERIAL E MÉTODOS}

Esta pesquisa foi desenvolvida avaliando-se fêmeas da raça Anglonubiana no rebanho do Departamento de Zootecnia no Centro de Ciências Agrárias da Universidade Federal do Piauí (DZO/CCA/UFPI), Teresina, Piauí (latitude $05^{\circ} 05^{\prime} 21^{\prime \prime} \mathrm{S}$, longitude $42^{\circ} 48^{\prime} 07^{\prime \prime}$ W). Segundo classificação de Köppen, o clima da região é do tipo Aw', tropical chuvoso (megatérmico) de savana, com inverno seco e verão chuvoso. A precipitação pluviométrica média anual tem sido até $1.365 \mathrm{~mm}$, sendo que predomina vegetação típica de cerrado e floresta mista, denominada mata de babaçu (SEMDEC, 2010).

Caracterizou-se o macroambiente da microrregião de Teresina entre 2008 e 2010, utilizando-se dados de temperatura, umidade relativa do ar e precipitação pluviométrica, cedidos pela Embrapa Meio-Norte, coletados em Estação Meteorológica localizada em Teresina, a uma distância de $2 \mathrm{~km}$ do rebanho caprino do DZO/CCA/UFPI. Com base nesses dados, caracterizaramse as condições ambientais, dividindose o ano em três épocas: chuvosa e quente (de dezembro a maio), seca com noite amena (junho e julho) e seca quente (de agosto a novembro), critério também utilizado por Oliveira (2009). Mensurou-se também a temperatura e umidade do ar no interior do aprisco com termohigrógrafo.

Os animais foram manejados em conjunto com os demais do rebanho, em sistema de criação semi-intensivo, sendo todos recolhidos ao aprisco às $12 \mathrm{hs}$, no período de coleta de dados e liberados para o pasto, as $08 \mathrm{hs}$ na manhã seguinte. $\mathrm{O}$ pastejo ocorreu em piquetes de tamanhos diversos, não excedendo a três hectares, em áreas de
Andropogon gayannus Kunth consorciado com árvores nativas $\mathrm{e}$ sombreamento natural, e também em piquetes com Panincum maximum Jacq. cv. Tanzânia e Brachiaria brizantha cv. Marandu, ambos irrigados e desprovidos de sombreamento. Utilizou-se também capim-elefante (Pennisetum purpureum Schum.) como volumoso distribuído no cocho e feno de Cynodon spp. (Tifton $85)$.

As matrizes em lactação foram suplementadas com ração comercial contendo $16 \%$ de proteína bruta, para manutenção da condição corporal. As crias receberam suplementação alimentar a partir dos 20 dias de vida e não acompanhavam as mães ao pasto, sendo desmamadas aos quatro meses de idade. Água e sal mineral para mães e crias foram disponibilizados apenas no aprisco.

Realizou-se manejo sanitário para controle de verminose, consistindo em cinco vermifugações ao longo do ciclo de produção da matriz, tendo como referência o estágio fisiológico. A primeira aplicação ocorrendo no início da estação de monta, a segunda no terço final da gestação, a terceira após 0 parto, a quarta aos 60 dias desta e a quinta no desmame.

A coleta de dados foi realizada em fêmeas submetidas à estação de monta em agosto e setembro, com o terço final de gestação ocorrendo em novembro e dezembro e lactação em fevereiro. Registrou-se a temperatura retal (TR), frequência cardíaca (FC) e respiratória (FR), mensuradas no mesmo animal, estando ele "não prenhe" em setembro, "prenhe" em novembro e em "lactação" em fevereiro. As mesmas características foram mensuradas nas marrãs nos mesmos períodos.

Os animais foram amostrados aleatoriamente na estação de monta, priorizando a escolha de fêmeas com 
condição corporal similar, sendo escolhidos seis animais de cada classe de idade (cabras com mais de 72 meses, de 36 a 72, entre 18 e 36 e marrãs de 12 a 15 meses). Nestes animais a mensuração dos parâmetros fisiológicos ocorreu em duas semanas e em três dias alternados. As mensurações foram realizadas com os animais contidos e acomodados no interior do aprisco, no horário de $14 \mathrm{hs}$ as $17 \mathrm{hs}$, na sequência: FR, FC e TR. Para uniformizar a influência da contenção dos animais sobre a mensuração das frequências cardíaca $\mathrm{e}$ respiratória, foram descartadas as mensurações iniciais.

A temperatura retal foi avaliada utilizando-se termômetro clínico veterinário digital, com escala até $43,9^{\circ} \mathrm{C}$, introduzido na ampola retal do animal, permanecendo até a emissão de sinal sonoro indicador de estabilização da temperatura. A frequência cardíaca foi obtida com uso de estetoscópio manual posicionado na região torácica esquerda à altura do arco aórtico, durante um minuto e expressa em batimentos por minuto. A frequência respiratória consistiu na observação e contagem dos movimentos do flanco do animal com o auxílio de cronômetro, durante 30 segundos sendo o valor multiplicado por dois e expresso em movimentos por minuto. Nas leituras da FC e FR foram utilizados dois avaliadores, registrandose a média.

Em cada época de coleta foram registrados também o peso do animal em balança com capacidade para $200 \mathrm{~kg}$ e o escore da condição corporal, atribuindo-se notas de 1 a 5 , por três avaliadores, simultaneamente, conforme critério de Morand-Fehr \& Hervieu (1999).

As análises estatísticas foram realizadas com o procedimento GLM do programa SAS (STATISTICAL ANALYSIS SYSTEMS, 2004), utilizando-se análise de variância pelo método dos quadrados mínimos. O modelo estatístico incluiu os efeitos época do ano (confundido com estágio fisiológico do animal) e classe de idade da cabra, com análise em fatorial $3 \times 4$, com seis repetições. As médias foram comparadas pelo teste SNK a 5\% de probabilidade.

\section{RESULTADOS E DISCUSSÃO}

O aprisco suspenso, coberto com telha de amianto, local de manejo dos animais do rebanho avaliado, não se mostrou eficiente em termos de melhoria de ambiência, de forma a reduzir o potencial de estresse por calor, pois a temperatura média do ar no seu interior, no horário da manhã (Tabela 1) foi superior à temperatura ambiente registrada em Teresina na Estação Meteorológica da Embrapa Meio-Norte (Tabela 2). Além disso, apenas na parte da manhã o valor da temperatura ambiente se apresentou na faixa de 20,6 a $27,8^{\circ} \mathrm{C}$, que foi considerada por Lucena et al. (2013) como faixa de conforto térmico para caprinos das raças Canindé e Moxotó, que são nativas da região. Logo, para essa região deve ser recomendado o uso de instalações adequadas a ambientes com temperaturas elevadas, mesmo se destinado a sistema de criação extensivo.

A umidade relativa do ar na região foi elevada na parte da manhã no período chuvoso e com tendência de redução na época seca e quente, numa relação direta com a precipitação pluviométrica e inversa com $\mathrm{o}$ aumento da evapotranspiração potencial (Tabela 2), tendência que também se estendeu ao interior do Aprisco, onde a temperatura média do ar foi superior a $36,9^{\circ} \mathrm{C}$ na parte da tarde (Tabela 1). Este resultado se mostrou similar ao que foi constatado 
por Rocha et al. (2009), com a temperatura média superando $36,5^{\circ} \mathrm{C}$ durante a tarde. Ambos se assemelham a outras literaturas que avaliaram caprinos no Nordeste e que constataram efeito significativo do turno do dia e/ou da época do ano sobre algumas variáveis ambientais ou sobre parâmetros fisiológicos dos animais (LUCENA et al., 2013; PEREIRA et al., 2011; SILVA et al., 2011; SILVA et al., 2010; SOUZA et al., 2007; SANTOS et al., 2005). Portanto, tais resultados podem ser vistos como indicadores consistentes do quanto a raça a ser indicada para criação na região deva ser formada por animais adaptados à ambiente quente, de forma a não necessitar de custos elevados para modificação ambiental, pois estarão expostos nessa região a condição térmica com alto poder de estresse por calor na maior parte do ano, nesse caso, considerando-se que, sob temperatura superior a $31,6^{\circ} \mathrm{C}$ os caprinos tendem elevar a frequência cardíaca $\mathrm{e}$ respiratória e a temperatura da pele, caracterizando situação de estresse térmico, segundo Lucena et al. (2013).

Tabela 1. Média e desvio-padrão das variáveis climáticas registradas no aprisco experimental

\begin{tabular}{lcccc}
\hline Época do ano ${ }^{1}$ & $\begin{array}{c}\text { Temperatura } \\
\text { ambiente na } \\
\text { manhã }\left({ }^{\circ} \mathrm{C}\right)\end{array}$ & $\begin{array}{c}\text { Temperatura } \\
\text { ambiente na tarde } \\
\left({ }^{\circ} \mathrm{C}\right)\end{array}$ & $\begin{array}{c}\text { Umidade relativa } \\
\text { média do ar }(\%)\end{array}$ & $\begin{array}{c}\text { Umidade } \\
\text { relativa mínima } \\
\text { do ar }(\%)\end{array}$ \\
\hline $\begin{array}{l}\text { Chuvosa e quente } \\
\text { Seca com noite }\end{array}$ & $26,9 \pm 2,6$ & $36,9 \pm 2,9$ & $89,3 \pm 6,8$ & $51,9 \pm 8,9$ \\
amena & $26,2 \pm 2,3$ & $37,3 \pm 2,9$ & $69,2 \pm 14,0$ & $31,6 \pm 9,9$ \\
Seca e quente & $28,8 \pm 2,1$ & $39,9 \pm 1,9$ & $65,2 \pm 9,4$ & $22,8 \pm 9,2$ \\
\hline
\end{tabular}

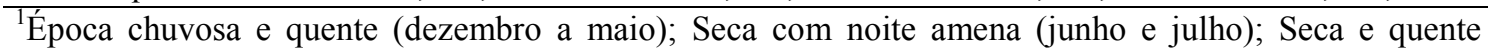
(agosto a novembro).

Tabela 2. Média e desvio-padrão das variáveis meteorológicas durante a manhã, no período de 2008 a 2010, em Teresina, PI

\begin{tabular}{lcccc}
\hline Época do ano ${ }^{1}$ & $\begin{array}{c}\text { Temperatura } \\
\text { ambiente na } \\
\text { manhã }\left({ }^{\circ} \mathrm{C}\right)\end{array}$ & $\begin{array}{c}\text { Temperatura } \\
\text { ambiente na tarde } \\
\left({ }^{\circ} \mathrm{C}\right)\end{array}$ & $\begin{array}{c}\text { Umidade relativa } \\
\text { média do ar }(\%)\end{array}$ & $\begin{array}{c}\text { Umidade relativa } \\
\text { mínima do ar }(\%)\end{array}$ \\
\hline $\begin{array}{l}\text { Chuvosa e } \\
\text { quente }\end{array}$ & $26,7^{\mathrm{b}}$ & $85,4^{\mathrm{a}}$ & $1.113,7^{\mathrm{a}}$ & $2,96^{\mathrm{b}}$ \\
$\begin{array}{l}\text { Seca com noite } \\
\text { amena }\end{array}$ & $26,5^{\mathrm{b}}$ & $76,1^{\mathrm{b}}$ & $35,6^{\mathrm{b}}$ & $3,39^{\mathrm{b}}$ \\
Seca e quente & $28,7^{\mathrm{a}}$ & $63,7^{\mathrm{c}}$ & $198,1^{\mathrm{b}}$ & $4,54^{\mathrm{a}}$ \\
\hline
\end{tabular}

Fonte: Informações cedidas pela Embrapa Meio-Norte.

${ }^{1}$ Época chuvosa e quente (dezembro a maio); Seca com noite amena (junho e julho); Seca e quente (agosto a novembro).

Médias seguidas pela mesma letra minúscula na coluna não diferem entre si pelo teste SNK a 5\%.

Em relação a forma proposta para a caracterização das condições ambientais ao longo do ano na região, constatou-se que a época considerada como chuvosa se mostrou bem distinta da seca no período de 2008 a 2010 , pois as quatro 
características analisadas diferiram significativamente entre elas $(\mathrm{P}<0,05)$. A época seca se apresentou com maior temperatura ambiente e evapotranspiração potencial, mas com menor precipitação pluviométrica e umidade relativa do ar. A iniciativa de incluir uma época "seca com noite amena", como intermediária entre a "seca" e a "chuvosa", de forma a caracterizar melhor as condições ambientais na região, como sugeriu Oliveira (2009), não se mostrou muito eficaz, pois ela diferiu da época "chuvosa e quente" apenas na umidade do ar e na precipitação pluviométrica, que foram elevadas no primeiro semestre do ano.

Com base nas condições ambientais constatadas nesta pesquisa e também em literaturas nas quais consta que o fluxo de calor por processo não evaporativo (condução, convecção e radiação) do animal para o ambiente, ocorre mediante presença de gradiente de temperatura (SILVA, 2000; SOUSA et al., 2005; INGRAM \& MOUNT, 1975), considerase que a busca da homeotermia corporal por vasodilatação periférica tendeu a apresentar baixa eficiência, pois $\mathrm{o}$ gradiente entre a temperatura corporal e a ambiental foi pequeno no interior do aprisco na parte da tarde. Diante disso, convém recomendar para a construção das instalações, o uso de material com cores com menor capacidade de irradiar calor.

Ao se levar em consideração o valor da temperatura retal apresentada pelas fêmeas Anglonubianas no período de setembro a fevereiro, cuja variação foi de $38,78^{\circ} \mathrm{C}$ nas marrãs a $39,5^{\circ} \mathrm{C}$ nas cabras velhas, durante a lactação (Tabela 3), porém, sem ultrapassar a faixa de variação de 38,5 a $39,7^{\circ} \mathrm{C}$, considerada por Dukes \& Swenson (2006) como normal para caprinos em produção e que a mensuração ocorreu na parte da tarde que é o período mais quente do ano na região, o status térmico apresentado pelos animais pode ser visto como uma boa indicação de adaptação dessa raça a locais com temperaturas elevadas, concordando com literaturas que avaliaram essa raça no Nordeste (SILVA et al., 2010; SILVA et al., 2006; SILVA et al., 2005; SOUSA et al., 2005; SANTOS et al., 2005).

$\mathrm{O}$ custo da busca de adequação às condições ambientais da região, consequentemente demonstrar adaptação, está bem refletida no comportamento observado nas frequências cardíaca e respiratória, sendo que a variação de 74,66 a 88,75 bat./min. observada na frequência cardíaca (Tabela 3) excedeu o limite superior da faixa de 70 a 80 bat./min., citada por Dukes \& Swenson (2006) como normal para animais adultos na ausência de estresse e a variação de 29,11 a 45,51 mov./min. na frequência respiratória também excedeu o limite superior de 12 a 25 mov./min., considerado normal para caprinos quando criados em condições de conforto térmico (KOLB, 1987). Portanto, os resultados concordam com afirmações de Lucena et al. (2013) e Pereira et al. (2011) que a frequência cardíaca e a respiratória mostram ser variáveis muito afetadas nos animais quando mantidos sob estresse térmico. Por sua vez, a frequência respiratória, variando de 29,11 nas marrãs a 45,51 mov./min. nas cabras de idade intermediária (Tabela 3), mostrou que os animais recorrem a esse artifício de forma efetiva para se adequar às condições ambientais presentes. Resultado esse que concorda com o de várias literaturas que tratam da resposta de caprinos a ambientes quentes, quanto a ser uma forma para manter a homeotermia (GOMES et al., 2008; SILVA et al., 2006; SANTOS et al., 
Rev. Bras. Saúde Prod. Anim., Salvador, v.15, n.1, p.160-171 jan./mar., 2014 http://www.rbspa.ufba.br ISSN 15199940

2005; SOUZA et al., 2005) e que consideram ser a variação dessa característica um bom indicador da capacidade de dissipação de calor pelos animais. Além disso, esses resultados dão consistência para se aceitar que a faixa normal de variação desse parâmetro seja mais elevada para caprinos manejados em regiões com prevalência de altas temperaturas.

Tabela 3. Média de características fisiológicas e de desempenho, em fêmeas da raça Anglonubiana, em Teresina, PI

\begin{tabular}{|c|c|c|c|c|c|c|}
\hline \multirow[b]{2}{*}{ Característica } & \multirow{2}{*}{$\begin{array}{c}\text { Mês da } \\
\text { mensuração }\end{array}$} & \multicolumn{3}{|c|}{ Idade da matriz } & \multirow[b]{2}{*}{ Marrã } & \multirow{2}{*}{$\begin{array}{l}\text { CV } \\
(\%)\end{array}$} \\
\hline & & $\begin{array}{c}\text { Mais de } 72 \\
\text { meses }\end{array}$ & $\begin{array}{c}36 \text { a } 72 \\
\text { meses }\end{array}$ & $\begin{array}{l}\text { Menos de } \\
36 \text { meses }\end{array}$ & & \\
\hline \multirow{3}{*}{$\begin{array}{l}\text { Temperatura } \\
\text { Retal }\left({ }^{\circ} \mathrm{C}\right)\end{array}$} & Setembro $^{* *}$ & $38,88^{\mathrm{Ba}^{*}}$ & $38,94^{\mathrm{Aa}}$ & $38,86^{\mathrm{Ba}}$ & $38,78^{\mathrm{Aa}}$ & \multirow{3}{*}{0,54} \\
\hline & Dezembro & $39,18^{\mathrm{Aba}}$ & $39,04^{\mathrm{Aa}}$ & $39,05^{\mathrm{Aba}}$ & $39,04^{\mathrm{Aa}}$ & \\
\hline & Fevereiro & $39,50^{\mathrm{Aa}}$ & $39,22^{\mathrm{Aab}}$ & $39,34^{\mathrm{Aa}}$ & $38,88^{\mathrm{Ab}}$ & \\
\hline \multirow{3}{*}{$\begin{array}{l}\text { Frequência } \\
\text { Cardíaca } \\
\text { (bat./min) }\end{array}$} & Setembro & $74,66^{\mathrm{Ba}}$ & $75,82^{\mathrm{Ba}}$ & $75,42^{\mathrm{Ba}}$ & $76,17^{\mathrm{Aa}}$ & \multirow{3}{*}{6,21} \\
\hline & Dezembro & $84,37^{\mathrm{Aa}}$ & $87,50^{\mathrm{Aa}}$ & $86,37^{\mathrm{Aa}}$ & $78,53^{\mathrm{Aa}}$ & \\
\hline & Fevereiro & $86,80^{\mathrm{Aa}}$ & $88,00^{\mathrm{Aa}}$ & $88,75^{\text {Aa }}$ & $79,16^{\mathrm{Aa}}$ & \\
\hline \multirow{3}{*}{$\begin{array}{l}\text { Frequência } \\
\text { Respiratória } \\
\text { (mov./min) }\end{array}$} & Setembro & $44,66^{\mathrm{Aa}}$ & $45,51^{\mathrm{Aa}}$ & $45,44^{\mathrm{Aa}}$ & $43,22^{\mathrm{Aa}}$ & \multirow{3}{*}{15,98} \\
\hline & Dezembro & $43,73^{\mathrm{Aa}}$ & $43,13^{\mathrm{Aa}}$ & $44,53^{\mathrm{Aa}}$ & $38,43^{\mathrm{Aa}}$ & \\
\hline & Fevereiro & $36,06^{\mathrm{Aa}}$ & $35,61^{\text {Aa }}$ & $38,44^{\mathrm{Aa}}$ & $29,11^{\mathrm{Ba}}$ & \\
\hline \multirow{3}{*}{$\begin{array}{l}\text { Peso corporal } \\
(\mathrm{kg})\end{array}$} & Setembro & $49,67^{\mathrm{Aa}}$ & $44,83^{\mathrm{Aab}}$ & $38,83^{\mathrm{Ab}}$ & $34,67^{\mathrm{Abc}}$ & \multirow{3}{*}{10,18} \\
\hline & Dezembro & $51,83^{\mathrm{Aa}}$ & $49,00^{\mathrm{Aa}}$ & $46,83^{\mathrm{Aa}}$ & $39,50^{\mathrm{Ab}}$ & \\
\hline & Fevereiro & $46,17^{\mathrm{Aa}}$ & $41,00^{\mathrm{Aab}}$ & $38,50^{\text {Aab }}$ & $36,17^{\mathrm{Ab}}$ & \\
\hline \multirow{3}{*}{$\begin{array}{l}\text { Escore } \\
\text { corporal (nota } \\
1 \text { a } 5 \text { ) }\end{array}$} & Setembro & $2,88^{\mathrm{Aa}}$ & $2,90^{\mathrm{Aa}}$ & $3,05^{\mathrm{Aa}}$ & $3,05^{\mathrm{Aa}}$ & \multirow{3}{*}{5,98} \\
\hline & Dezembro & $2,83^{\mathrm{Aa}}$ & $2,90^{\mathrm{Aa}}$ & $2,92^{\mathrm{Aa}}$ & $2,92^{\mathrm{Aa}}$ & \\
\hline & Fevereiro & $2,58^{\mathrm{Aab}}$ & $2,53^{\mathrm{Bb}}$ & $2,73^{\mathrm{Aab}}$ & $2,87^{\mathrm{Aa}}$ & \\
\hline
\end{tabular}

${ }^{*} \mathrm{Na}$ característica, as médias com mesma letra maiúscula na coluna (efeito época) e minúscula na linha (efeito de idade), não diferem pelo teste SNK a $5 \%$.

${ }^{* *}$ Setembro - cabras não prenhes; Dezembro - cabras prenhes; Fevereiro - cabras em lactação.

$\mathrm{CV}=$ coeficiente de variação.

A tendência significativa de elevação da temperatura retal e da frequência cardíaca, verificadas nas cabras gestantes em dezembro e nas lactantes em fevereiro $(\mathrm{P}<0,05)$, pode também ser atribuída à maior atividade metabólica que ocorre na gestação e na lactação (MUNDIM et al., 2007; RODRIGUES et al., 2007). Porém, pareceu que essa elevação de temperatura corporal não implicou em sensação de desconforto térmico suficiente para forçar os animais a recorrer a elevação simultânea da frequência respiratória para manter a homeotermia.

A tendência de elevação da temperatura retal e da frequência cardíaca nas cabras de setembro para fevereiro, que se mostrou significativa nos animais com mais de 72 meses de idade e nas primíparas (de 18 a 36 meses), demonstra indícios de influência da idade associada a maior atividade metabólica que ocorre na gestação e na lactação, pois nas marrãs que se mantiveram sob o mesmo estágio fisiológico ao longo do período 
estudado, essa tendência não foi significativa $(\mathrm{P}>0,05)$. Entretanto, como as cabras conseguiram manter a temperatura retal dentro da faixa normal para caprinos, mostra ser uma resposta de ajuste da cabra dessa raça a ambiente quente, evidenciando que, mesmo durante a prenhez as matrizes suportam carga térmica corporal elevada.

A constatação da temperatura retal e da frequência cardíaca com valores elevados durante a gestação ocorrida em dezembro e na lactação em fevereiro, meses nos quais a temperatura ambiente tendeu a ser menor que em setembro, enquanto a umidade relativa foi mais alta, demonstra que essa condição ambiente associada a esses dois estágios fisiológicos expõem os animais a estresse por temperatura elevada, concordando com Resende et al. (2008). Diante disso parece inadequado recomendar o uso de manejo reprodutivo para a raça Anglonubiana que resulte na ocorrência de gestação e/ou lactação em setembro na região, mesmo sendo pequena a interferência do fotoperíodo na reprodução.

Ao se analisar o tamanho dos animais, verificou-se que o peso corporal das fêmeas no rebanho variou de $34,7 \mathrm{~kg}$ nas marrãs a $51,8 \mathrm{~kg}$ nas cabras velhas no terço final da gestação $(\mathrm{P}<0,05), \operatorname{logo}$, no rebanho avaliado os animais apresentam porte que atende às exigências da raça. Porém, constatou-se que o peso corporal das cabras tendeu a crescer com a gestação e reduzindo na lactação, mas de forma não significativa $(\mathrm{P}>0,05)$.

Nas marrãs o peso tendeu a apresentar maior valor na mensuração realizada em dezembro e, por serem feitas nos mesmos animais, pode-se afirmar que a condição de ambiente nesse mês favoreceu mais aos animais do que a condição presente nas duas outras datas consideradas. Essa afirmação encontra respaldo no comportamento da condição corporal, pois o menor valor observado em fevereiro pode ser atribuído à incidência de verminose, que foi confirmado nessa época no rebanho da UFPI por Silva (2011).

Nas cabras, o escore corporal não acompanhou integralmente $\mathrm{o}$ comportamento de aumento verificado no peso corporal, sendo que o maior valor não ultrapassou 3,05 nos animais vazios em setembro e ficou em torno de 2,5 durante a lactação. Logo, indicou que nessa pesquisa as cabras estavam magras, principalmente na lactação, segundo o critério de formação de classes por escore utilizado por Barbosa et al. (2009).

$\mathrm{Na}$ perspectiva de se considerar que animais com baixa condição corporal, de certa forma, podem ser vistos como estando sob estresse, que nesse caso é decorrente de déficit de energia no estágio em que se encontram, foi constado queda no escore da cabra à medida que se aproximou do fim da gestação e início da lactação. Esse comportamento foi explicado por Rodrigues et al. (2007) e Barbosa et al. (2009), como consequência da mobilização de energia para atender ao desenvolvimento do feto e depois a lactação, sendo este um processo que predispõe os animais a maior sensibilidade a agentes estressores, principalmente patológicos. Assim, como essa mobilização ocorreu em cabras classificadas como magras, certamente foi um fator a mais de estresse para os animais, mas que não ocorreu com as marrãs que apresentaram peso médio superior a $70 \%$ do valor do animal adulto e a condição corporal variou menos que nas cabras $(\mathrm{P}>0,05)$.

$\mathrm{Na}$ análise da relação da condição corporal do animal com os parâmetros fisiológicos, como a alteração da 
condição corporal é uma estimativa precisa de mudança nas reservas energéticas do animal (RODRIGUES et al., 2007; BARBOSA et al., 2009), o valor inferior a 3,0 na gestação, indica que não ocorreu acúmulo de gordura nessa fase que possa justificar alteração nos parâmetros fisiológicos. Porém, como a função reprodutiva é uma das primeiras a sofrer com situações de balanço energético negativo, a condição corporal baixa deve ser vista como indicativo que o animal estava submetido à produção sob esse fator de estresse.

$\mathrm{Na}$ lactação o escore corporal ficou em torno de 2,5 pontos, colocando as cabras entre a classe de animais magros a moderado (RODRIGUES et al., 2007; BARBOSA et al., 2009) e indicando situação de falha no balanço entre a disponibilidade de nutrientes e o requerimento dos animais, com isso as cabras precisaram aumentar a atividade metabólica para atender a demanda das crias e também a própria mantença, fato que pode estar relacionado com a elevação da temperatura retal $\mathrm{e}$ frequência cardíaca verificadas nas cabras no mês de fevereiro.

Ao se observar diariamente o comportamento das cabras gestantes e não gestantes durante sua permanência no aprisco, constatou-se que o desconforto externado pelos animais tendeu a crescer mais em razão da concorrência por espaço entre o feto e os órgãos do sistema respiratório $\mathrm{e}$ digestório, do que pelo estresse decorrente de temperatura elevada, pois no terço final da gestação as cabras gestantes permaneceram deitadas em momentos de repouso e a frequência respiratória foi menor em comparação com as cabras vazias. Convém considerar nessa argumentação que a tolerância ao calor em clima tropical é um dos motivos que faz os animais apresentarem comportamentos conforme suas origens e adaptação, sendo que, sob temperaturas mais elevadas os animais tendem a ficar mais tempo com comportamento que facilita a perda do calor corporal excedente, de forma a buscar manter a homeostase corporal. Porém, em ambientes mais amenos, tendem a apresentar comportamento mais propício à melhora de produção, indicando que estariam sob maior conforto (MAC-LEAN et al., 2011).

Com relação à influência da idade sobre os parâmetros fisiológicos, observou-se que as cabras não alteraram a temperatura retal $(\mathrm{P}>0,05)$, ou seja, sem influência da idade no mesmo mês do ano, mesmo elas diferindo em peso corporal $(\mathrm{P}<0,05)$. Já as marrãs apenas no mês de fevereiro diferiram das cabras mais velhas e das mais novas $(\mathrm{P}<0,05)$. $\mathrm{O}$ fato das marrãs não diferirem das cabras com idade entre três e seis anos estaria demonstrando que, na raça Anglonubiana, cabras velhas e primíparas em lactação estão mais sujeitas a estresse térmico que aquelas com capacidade de produção estabilizada.

Como as marrãs já atingiram idade e peso para reprodução, com valor correspondendo a $70 \%$ do peso de cabra adulta, a diferença significativa verificada em relação às cabras, indicou que na gestação e lactação os animais se mostram mais sensíveis a estresse por elementos do clima como a temperatura alta e umidade, pois nesses estágios fisiológicos é maior a atividade metabólica dos animais, concordando com Brito et al. (2006).

Cabras da raça Anglonubiana, independentemente da idade e estágio fisiológico, recorrem à elevação da frequência respiratória para complementar o processo de dissipação de calor no mês de setembro na região. 
A idade, o peso e a condição corporal do animal parecem influenciar pouco a resposta que apresentam às condições climáticas da microrregião de Teresina. As alterações nas características indicadoras de status térmico do animal, mais acentuadamente na temperatura retal, demonstram que o período do ano mais favorável à homeotermia corporal seja destinado a ocorrência da gestação e lactação.

\section{AGRADECIMENTOS}

Ao CNPq, pela concessão da bolsa de estudos para o curso de Mestrado.

\section{REFERÊNCIAS}

AZEVEDO, M.; PIRES, M.F.A.; SATURNINO, H.M.; LANA, A.M.Q.; SAMPAIO, I.B.M.; MONTEIRO, J.B.N.; MORATO, L.E. Estimation of Upper Critical Levels of the

Temperature-Humidity Index for $1 / 2,3 / 4$ $\mathrm{e}^{7 / 8}$ Lactating Holstein-Zebu Dairy Cows. Revista Brasileira de

Zootecnia, v.34, n.6, p.2000-2008, 2005.

BAÊTA, F.C.; SOUZA, C.F. Ambiência em edificações rurais: conforto animal. Viçosa, MG: Universidade Federal de Viçosa, 1997. $246 p$.

BARBOSA, P.B.; RODRIGUES, M.T.; GUIMARÃES, J.D.; MAFFILI, V.V.; AMORIM, L.S.; GARCEZ NETO, A.F. Body condition and metabolic profile of Alpine goats at the onset of lactation.

Revista Brasileira de Zootecnia, v.38, n.10, p.2007-2014, 2009.
BRITO, M.A.; GONZÁLEZ, F.D.; RIBEIRO, L.A.; CAMPOS, R.; LACERDA, L.; BARBOSA, P.R.; BERGMANN, G. Blood and milk composition in dairy ewes from southern Brazil: variations during pregnancy and lactation. Ciência

Rural, v.36, n.3, p.942-948, 2006.

DUKES, H.H.; SWENSON, H.J.

Fisiologia dos Animais Domésticos. 12.ed. Rio de Janeiro: Guanabara Koogan, 2006. 946p.

GOMES, C.A.V.; FURTADO, D.A.; MEDEIROS, A.N.; SILVA, D.S.; PIMENTA FILHO, E.C.; LIMA JÚNIOR, V. Effect of thermal ambient and feed supplementation levels on physiologic parameters of Moxotó goats. Revista Brasileira de Engenharia Agrícola e Ambiental, v.12, n.2, p.213-219, 2008.

INGRAM, D.L.; MOUNT, L.E. Man and animals in hot environments. New York: Springer-Verlag, 1975. $185 \mathrm{p}$.

INSTITUTO BRASILEIRO DE GEOGRAFIA E ESTATÍSTICA IBGE. [2010]. Produção da pecuária municipal. Disponível em: $<$ www.ibge.gov.br $>$. Acesso em: 30 out. 2011.

KOLB, E. Fisiologia Veterinária. 4.ed. Rio de Janeiro: Guanabara Koogan, 1987. 612p.

LUCENA, L.F.A.; FURTADO, D.A.; NASCIMENTO, J.W. B.; MEDEIROS, A.N.; SOUZA, B.B. Physiological responses of native goats maintained in thermoneutral temperature and thermal stress. Revista Brasileira de Engenharia Agrícola Ambiental, v.17, n.6, p.672-679, 2013. 
MAC-LEAN, P.A.B.; BARBOSA, O.R.; JOBIM, C.C.; GASPARINO, E.; SANTOS, G.T.; FARIA, L.A.N.

Artificial shade and method of concentrate supply in behavior and in performance of calves. Acta Scientiarum. Animal Sciences, v.33, n.4, p.409-415, 2011.

MORAND-FEHR, P.; HERVIEU, J. Apprécier l'état corporel des chèvres: Intérêt et méthod. Réussir La Chèvre, n.231, p. 22-34, 1999.

MUNDIM, A.V.; COSTA, A.S.; MUNDIM, S.A.P.; GUIMARÃES, E.C.; ESPINDOLA, F.S. Influence of parity and stage of lactation on the blood biochemical profile of Saanen goats. Arquivo Brasileiro Medicina Veterinária e Zootecnia, v.59, n.2, p.306-312, 2007.

OLIVEIRA, A.N.; SELAIVEVILLARROEL, A.B.; MONTE, A.L.S.; COSTA, R.G.; COSTA, L.B.A. Evaluation of carcass characteristics of crossbred Anglo-Nubian, Boer and undefined breed goats. Ciência Rural, v.38, n.4, p.1073-1077, 2008.

OLIVEIRA, F.S. Termorregulação e adaptabilidade climática de ovinos Sem Padrão Racial Definido e da raça Marota na sub-região Meio-Norte do Brasil. 2009. 52f. Dissertação (Mestrado em Ciência Animal) Universidade Federal do Piauí, Teresina.

PEREIRA, G.M.; SOUZA, B.B.; SILVA, A.M.A.; ROBERTO, J.V.B. Determination of Saanen goats breed physiological parameters in paraiban Semi-Arid. Revista Verde, v.6, n.1, p.83 - 88. 2011.
RESENDE, K.T.; SILVA, H.G.O.; LIMA, L.D.; TEIXEIRA, I.A.M.A. Avaliação das exigências nutricionais de pequenos ruminantes pelos sistemas de alimentação recentemente publicados. Revista Brasileira de Zootecnia, v.37, p.161-177, 2008. Supl. Esp.

ROCHA, R.R.C.; COSTA, A.P.R.; AZEVEDO, D.M.M.R.;

NASCIMENTO, H.T.S.; CARDOSO, F.S.; MURATORI, M.C.S.; LOPES, J.B. Climatic adaptability of Saanen and Azul goats in Brazilian Middle-North. Arquivo Brasileiro de Medicina Veterinária e Zootecnia, v.61, n.5, p.1165-1172, 2009.

RODRIGUES, C.A.F.; RODRIGUES, M.T.; BRANCO, R.H.; CARVALHO, G.R.; TORRES, R.A.; TORRES FILHO, R.A. Effects of body condition score and dietary energy levels on performance of pregnant dairy goats.

Revista Brasileira de Zootecnia, v.36, n.4, p.945-952, 2007.

SANTOS, F.C.B.; SOUZA, B.B.; ALFARO, C.E.P.; CÉZAR, M.P.; PIMENTA FILHO, E.C.; ACOSTA, A.A.A.; SANTOS, J.R.S. Adaptability of exotic goat and naturalized to the climatic conditions of the tropic semiarid brazilian norheast. Ciência e Agrotecnologia, v.29, n.1, p.142-149, 2005.

SARMENTO, J.L.R.; PIMENTAFILHO, E.C.; RIBEIRO, M.N.; ARAÚJO, C.V.; BREDA, F.C.; PIRES, A.V.; TORRES FILHO, R.A.; TORRES, R.A. Genetic and environmental factors affecting the kidding interval of dairy goats in the semi-arid Northeastern. Revista

Brasileira de Zootecnia, v.32, n.4, p.875-879, 2003. 
Rev. Bras. Saúde Prod. Anim., Salvador, v.15, n.1, p.160-171 jan./mar., 2014 http://www.rbspa.ufba.br ISSN 15199940

STATISTICAL ANALYSIS

SYSTEMS. SAS/STAT. User's guide.

Versão 9.1.3. Cary: SAS Institute, 2004.

SECRETARIA MUNICIPAL DE DESENVOLVIMENTO ECONÔMICO E TURISMO - SEMDEC. [2010].

Perfil de Teresina: econômico, social, físico e demográfico. Disponível em:

$<$ www.teresina.pi.gov.br/portalpmt/orga o/SEMDEC/doc/20100709-336-1461-

D.pdf>. Acesso em: 23 ago. 2011.

SILVA, C.M.B.A.; SOUZA; B.B.; BRANDÃO, P.A.; MARINHO, P.V.T.; BENÍCIO, T.M.A. Effect of the semiarid climatic conditions on the physiological behavior of F1 Saanen $\mathrm{x}$ Boer crossbred goats. Revista

Caatinga, v.24, n.4, p.195-199, 2011.

SILVA, E.M.N.; SOUZA, B.B.; SILVA, G.A.; CEZAR, M.F.; SOUZA, W.H.; BENÍCIO, T.M.A.; FREITAS, M.M.S. Evaluation of the adaptability of goats exotic and native of the semiarid of Paraiba. Ciência e

Agrotecnologia, v.30, n.3, p.516-521, 2006.

SILVA, E.M.N.; SOUZA, B.B.; SOUSA, O.B.; SILVA, G.A.; FREITAS, M.M.S. Evaluation of adaptability of goats to Semiarid through physiologic parameters and structures of the tegument. Revista Caatinga, v.23, n.2, p.142-148, 2010.
SILVA, N.C.S. Efeitos ambientais que interferem no endoparasitismo em matrizes da raça Anglo-nubiana em Teresina-Piauí. 2011. 62f. Dissertação (Mestrado em Ciência Animal) Universidade Federal do Piauí, Teresina.

SILVA, R.G. Introdução à bioclimatologia animal. São Paulo: Nobel, 2000. 286p.

SOUZA, B.B.; SILVA, R.M.N.; MARINHO, M.L.; SILVA, G.A.; SILVA, E.M.N.; SOUZA, A.P. Physiological parameters and heat tolerance index of sindi breed bovine in the semi-arid of Paraiba. Ciência e Agrotecnologia, v.31, n.3, p.883-888, 2007.

SOUZA, E.D.; SOUZA, B.B.; SOUZA, W.H.; CEZAR, M.F.; SANTOS, J.R.; TAVARES, G.P. Determination of the physiologic parameters and thermal gradient of different genetic groups of goats from semi-arid region. Ciência e Agrotecnologia, v.29, n.1, p.177-184, 2005.

Data de recebimento: $22 / 08 / 2013$

Data de aprovação: 24/03/2014 